\title{
The effects of public diplomacy on country identity in countries with different language regions and cultures: The case of Switzerland
}

\author{
Diana Ingenhoff, University of Fribourg, DCM - Department of Mass Media and Communication \\ Research* \\ Dominique Richner, University of Fribourg, DCM - Department of Mass Media and Communication \\ Research* \\ *Corresponding author: diana.ingenhoff@unifr.ch
}

\begin{abstract}
The aim of this study is to explore the existing differences in (regional) country identity between the two biggest language regions of Switzerland, and the effects that differently-framed public diplomacy messages have on these country identities. To analyze the heterogeneous dimensions of regional country identity in the two language regions and the effects of public diplomacy messages, an experimental study with four different groups was conducted. The results show that a) even within one country, different language regions have differing country identities and give varying significance to different dimensions, b) these differences have an impact on how public diplomacy messages are perceived, and c) they also have an impact on the overall country identity of the recipients of these messages. Finally, we show that d) these impacts are moderated by the subjects' political opinions on an issue as well as the framing of the message itself.
\end{abstract}

Keywords

Partial Least Squares (PLS), Multi Group Analysis, Public Diplomacy, Country Identity, 4D Model, Mass Immigration Initiative

\section{Introduction}

With the advent of the digital era, the world has experienced huge changes. Digitalization and globalization have led to new ways of communication impacting upon public diplomacy. Public diplomacy is defined as "the way in which both government and private individuals and groups influence directly or indirectly those public attitudes and opinions which bear directly on another government's foreign policy decisions" (Delany, 1968). In recent decades, the conditions for public diplomacy activities have changed drastically due to three different developments: The revolution in communication technologies, the revolution in politics - as many societies move towards becoming democracies, the means and extent of mass participation in political processes has changed and the process of globalization, which has led to a dissolving of national borders, to a new interconnectedness around the globe and to a massive compression of available time and space (Nye, 1990; Gilboa, 2008; Vickers, 2004).

Given these developments, Melissen (2005) identifies three major changes in public diplomacy: (1) a shift in public diplomacy motivated by the emergence of new actors, (2) a shift away from one-way communication towards dialogues and collaborations and (3) public diplomacy targets becoming increasingly interconnected. The advent of social media has been a particular catalyst for these changes by recasting public diplomacy from an asymmetrical top down communication into a potentially symmetrical communication by giving anyone the opportunity to speak up and take part in the public discourse (Harris, 2013). This last change poses a new challenge for public diplomacy: to align communication strategies, which were designed for a foreign public, with the concerns of a domestic public as well (Goodman \& Wang, 2006). In her article, 
Fitzpatrick (2012) comes to the conclusion that "if public diplomacy programs are to be managed strategically, the field of publics must include domestic publics. In this era of global connectedness and interdependence, the networks of influence that determine public diplomacy outcomes are no longer defined by geography or national borders."

Research in public diplomacy has acknowledged these developments and examined the subject in its new environment. However, the research still seems to be limited in different ways. Firstly, most research uses content analyses (Golan \& Viatchaninova, 2013; Mogensen, 2015; Strauss, Kruikemeier, van der Meulen, \& van Noort, 2015) or case studies (Khatib, Dutton, \& Thelwall, 2012; Smyth, 2001; Zhong \& Lu, 2013). There are not many experimental researches contributing to the understanding of causal relationships. Secondly, most of the research tests the status quo (Golan \& Viatchaninova, 2013; Khatib, Dutton, \& Thelwall, 2012; Smyth, 2001; Zhong \& Lu, 2013); in other words, it analyzes what public diplomacy actors do. The environmental changes, however, specifically illustrate the importance of the effects of public diplomacy activities on publics, an area which has not yet been addressed by any studies. The aim of this study, therefore, is to contribute to this research gap by exploring existing differences in country identities, taking the two biggest language regions of Switzerland as an example, and the effects that differently-framed public diplomacy messages have on these country identities. We understand country identity as the perception of the country held by the domestic public itself (Buhmann \& Ingenhoff, 2015a; Rusciano, Fiske-Rusciano, \& Wang, 1997). We show that the perception of the significant dimensions forming a country identity is different between the Frenchand German-speaking parts of Switzerland, is moderated by political opinions and attitudes, and that these differences have an influence on how public diplomacy messages are perceived.

\subsection{Country identity and the 4D model}

To understand the concept of country identity it is important to understand the differentiation between country image and country identity. We will refer to the country image when talking about the external perception, and to country identity when dealing with the perception of the domestic public (Buhmann \& Ingenhoff, 2015a; Rusciano, Fiske-Rusciano, \& Wang, 1997). Even though country identity is concerned with the domestic public only, it does not mean that this public is homogenous (Buhmann \& Ingenhoff, 2015a). If we think for example of Switzerland, with its various linguistic regions and its migrants, it becomes obvious that even within the domestic public there exists a very heterogeneous population. Thus country identity and country image cannot be completely separated, because "who we are cannot be completely separated from the perceptions others have of us and we have of others" (Hatch \& Schultz, 2000, p. 27). The two concepts are strongly interrelated, as there is a permanent negotiation between the country identity and the communicated images, which then shape the country identity and vice versa (Rusciano, 2003).

In order to measure country identity, the 4D Model of Buhmann and Ingenhoff (2015a) will be applied. This model is an integrative framework, developed to measure the multidimensional construct of country image and/or country identity. It draws on three basic concepts: the concept of national identity by Smith (1991) to describe the image object, the attitude theory by Ajzen and Fishbein (1980) to analyze the attitudes toward a country, and the model of reputation as a multidimensional construct (Eisenegger \& Imhof, 2008; Ingenhoff \& Sommer, 2007) to differentiate between the cognitive and affective components of the construct. It contains four dimensions: (1) The functional dimension of the model measures the beliefs about the competences and competitiveness of a country; (2) the normative dimension covers the beliefs regarding a country's norms, values and integrity; (3) the aesthetic dimension measures the beliefs regarding a country's attractiveness of culture and 
landscape; and (4) the emotional dimension consists of the attractiveness and fascination of a country and its citizens (Buhmann \& Ingenhoff, 2015a).

\subsection{Public diplomacy and framing theory}

In public diplomacy, communication is the primary tool. However, any message can be framed to achieve a different reaction. Until now, the framing theory has very rarely been used to describe or analyze public diplomacy activities. This lack of research on framing and theoretical infrastructures was also criticized by Entman (2008). This study therefore aims to test different frames as different public diplomacy strategies in order to examine their impacts on the audience. The framing type used in this study is attribute framing, "in which some characteristic of an object or event serves as the focus of the framing manipulation" (Levin, Schneider, \& Gaeth, 1998, p. 150). This means, for example, that an issue is addressed from only one perspective of the argument, while ignoring others. Entman (2008) identifies two variables moderating the effect of a framed strategy: magnitude and congruence. When the magnitude (i.e. the frequency and prominence) of an issue increases, influence can be exerted on public opinion about this issue. But when the issue is already prominent and frequently covered in the media, and the public is well informed, the effect of framing will reduce. With congruence, he means that a framed message has more effect if it is compatible with the dominant opinion of the public than that of an incongruently framed issue. Chong and Druckman (2007) showed that most individuals are less easily affected by frames which contradict their own opinion. However, if the issue is controversial and there is no dominant opinion, the framing effect is potentially high (Entman, 2008).

\subsection{The mass immigration initiative and cultural differentiation}

To analyze the impact of public diplomacy on country identity, the democratic vote on the mass immigration initiative in Swit- zerland in February 2014 serves as a stimulus. The initiative was launched by the Swiss People's Party (SVP) in 2011. Its aim was to restrict immigration to Switzerland with limits and quotas and to privilege Swiss nationals when hiring staff. This vote is interesting to analyze in multiple ways. Not only was the initiative of remarkable global interest, but it also showed a deeply divided country. Even though the vote in favor was surprisingly high - with $50.3 \%$ (BK, 2015) - it was obvious that it was not unanimous. Firstly, there was a difference in voting behavior between rural regions, who voted more in favor of the initiative (57.6\%), and urban centers, where people were less likely to vote yes (41.5\%). This indicates that the more urban the area voters lived in, the less likely it was that they voted yes. Secondly, and even more noticeable, are the differences between the country's language regions. While in the German-speaking part of Switzerland (52\%) and the Italian-speaking part $(68 \%)$ more than $50 \%$ voted yes, in the French-speaking part only $41.5 \%$ voted yes (BFS, $2015 \mathrm{~b}$ ). This is in line with the results of Schmid (1995), who shows that the German- and French-speaking parts of Switzerland differ in terms of their value systems, their political points of view, and their attitudes and identity. Although country identity has been attributed, amongst other things, to a territory, the symbolic factor of a common language plays an important role in the formation of a country identity (Smith, 1996). This leads to the research question (RQ) of this study:

$R Q$ : What is the impact of different public diplomacy strategies on country identity?

It can be assumed that the German- and French-speaking parts of Switzerland have different regional country identities, which could be a reason for the differing opinions expressed in the vote. ${ }^{1}$ Thus, the first hypothesis is:

1 This assumption could be valid for all language regions. In this study, however, the focus remains on the two largest language regions. 
H1: The country identities of the German-speaking and French-speaking parts of Switzerland differ, i. e. the values given to the different dimensions that form a country identity are different in the German- and French-speaking parts of Switzerland.

Public diplomacy messages are usually designed to affect the image foreign publics have of a country. If the domestic public, due to the new interconnectedness, also receive the message designed for the public abroad, it might also have an impact on them. Therefore, we can assume:

H2: Public diplomacy strategies influence country identity.

The framing mechanisms showed that there are two moderating variables, magnitude and congruence. The mass immigration initiative is a very controversial and prominent issue and the Swiss public is potentially very well-informed. In this case congruence might play a significant role as the federal council had to explain why there was a yes vote, even though there was also a lot of opposition. So, it can be assumed that the people who supported the initiative, based on a specific political opinion, reacted differently to such a message than the people who were opposed to it.

H3: Personal beliefs/political opinions on a communicated issue moderate the effect of a public diplomacy strategy on country identity.

Framing theory leads to the assumption that differently-framed public diplomacy messages will not have the same effect. Also, it is possible that the different frames have different effects on German- and French-speaking Swiss, or on supporters, opponents or undecided voters:

H4: Differently-framed public diplomacy messages have a different effect on country identity.
These hypotheses will be tested statistically to answer the research question of the study. To analyze causal relationships, it is reasonable to conduct an experiment. Therefore, the next section will be used to outline what method was used and why it was used.

\section{Method}

\subsection{Epistemic structure and operationalization of the construct}

Country identity is a complex latent construct with both reflective and formative indicators. The epistemic structure is dependent on the specification of these two types. The reflective indicators are the outcomes of the underlying construct and dropping one item should not alter the construct, as the items result from it. The direction of causality of the formative indicators, however, is from measure to construct. Hence dropping an item here would alter the construct, as the loss of the item might lead to the omission of an important part of the construct (Buhmann \& Ingenhoff, 2013; Fornell \& Bookstein, 1982; Jarvis, MacKenzie, \& Podsakoff, 2003).

Existing research concerning country image or country identity focuses mostly on reflective indicators (Ingenhoff \& Sommer, 2010). However, the cognitive dimensions - functional, normative and aesthetic - can be seen as "variables that make the underlying construct appear, not as outcomes" (Buhmann \& Ingenhoff, 2013, p. 68) and therefore should be treated as formative indicators. The emotional dimension, on the other hand, is an outcome of the country image or country identity and needs therefore to be operationalized by reflective items. The operationalization of this construct is based on the 4D Model of Buhmann and Ingenhoff (2015a). Given the argumentation above, "the exogenous constructs of the functional (FUNC), normative (NORM), and aesthetic (AEST) dimensions (cognitive country image component) were operationalized with formative indicators while the endogenous construct of the emotional (EMOT) dimension (affective country 
image component) was matched with reflective indicators" (Buhmann \& Ingenhoff, 2013, p. 69).

\subsection{Variables}

Political Attitudes and Personal Beliefs. First, the political attitudes and personal beliefs on the mass immigration initiative had to be measured as control variables. The items used here are from the 2015 Swiss election studies (Lutz, 2015). The subjects were first asked to relate themselves to the Swiss party they think match their opinions the most. Then they were asked to position themselves on a left-right scale with seven options. Lastly, they were asked how they voted (or if they didn't vote, how they would have voted) on the mass immigration initiative on $9^{\text {th }}$ February 2014.

Opinions of Switzerland (i.e. summary items). It is also necessary to test overall opinions of Switzerland before presenting the stimuli. In order to do so, the subjects were asked four questions, rating each of the four dimensions of country identity (functional, normative, aesthetic or emotional) on a seven point Likert-scale. These questions were also used as global items summarizing the four constructs, which helps in assessing the external validity of the formative constructs later on.

Country identity. To measure country identity the items of Buhmann and Ingenhoff (2013) were used. The set consists of 43 items: 19 for the functional dimension, 12 for the normative dimension, 8 for the aesthetic dimension (formative items) and 4 for the reflective specified dimension (emotional dimension).

\subsection{Experimental online survey}

To analyze the impact of public diplomacy on country identity, an experimental study with four different groups was conducted. This method was used because it can look for causalities. To control for intervening variables the subjects are randomly allocated to a group, so the groups are as similar as possible (Kühl, 2009). In order to be able to assign the differences between the groups to the stimuli, it is favorable to have a homogenous sample. The more similar the subjects are, the more clearly the differing outcome can be related to the measured causality. Different communication strategies on explaining the outcome of the vote on the mass immigration initiative served stimuli. They were created as newspaper articles in order to gauge their different impacts on the country identity. The public diplomacy strategies were fictional, each strategy referring to one dimension of the three independent dimensions of the 4D Model (functional, normative and aesthetic). Thus the subjects were divided into three treatment groups, with each group exposed to one of the three stimuli, and one control group.

The fictional newspaper articles were set in two different real newspapers, the French Le Figaro and the German Die Süddeutsche Zeitung. As the experiment took place in both the French- and German-speaking parts of Switzerland, the highest-circulation quality newspapers of each of the neighboring countries were chosen (Latzer, Aubert, Just, Korinth, \& Saurwein, 2012). To come up with the content of the newspaper articles, different existing newspaper articles dealing with the mass immigration initiative were used as orientation.

In order to test the hypotheses, we decided to choose the professional Swiss farmer's association, "IP-Suisse," as a sample. This was chosen because it is helpful in an experimental study to use a homogenous and large sample. Due to the huge number of IP-Suisse members, the sample consists of 1477 persons. The participants were randomly divided into the four groups, resulting in 395 subjects in the control group, 366 in the functional framed group, 343 in the normative framed group, and 373 in the aesthetic framed group. The sample is dominated by men (82\%), which is not surprising among farmers. The average age of the sample is 54 years $(S D=10.074)$. Although the sample is not representative of the Swiss population, members of IP-Suisse are nevertheless a suitable group to test the hypotheses. Farmers and agricultural employees are generally known to have political opinions on the issues of mass immigration and cul- 
tural differentiation, which lowers the risk of measuring opinions that do not actually exist. In fact, on a scale from one (left) to seven (right), $40.3 \%$ positioned themselves on the right end (six and seven), with $67.8 \%$ (69.4\% German-speaking, $60.6 \%$ French-speaking) answering that they voted (or would have voted) yes for the mass immigration initiative. Moreover, the farmer's association has members across all language regions of Switzerland, which allows for comparison of German-speaking and French-speaking Swiss. Of these 1477 subjects, $1218(82.5 \%)$ are from the German-speaking part of Switzerland and $259(17.5 \%)$ from the French-speaking part.

\section{Results}

In this study we test a variance-based partial least squares structural equation model (PLS-SEM), which offers more flexible modeling (Tenenhaus, Vinzi, Chatelin, \& Lauro, 2005). This way of modeling is especially useful when measuring formative constructs (Diamantopoulos \& Winklhofer, 2001; Monecke \& Leisch, 2012). We used the software Smart-PLS to conduct PLS-SEM, which also offers the option of calculating Multi Group Analyses (MGA) to analyze the significance of differences between groups in PLS-SEM. In the following, we will first present the different ways of evaluating the measurement models, both for the reflective construct of the emotional dimension and the formative constructs of the functional, normative and aesthetic dimensions. We will then analyze the structural models, and draw conclusions for testing our hypotheses.

\subsection{Measurement and structural model evaluation}

The analyses of the reflective construct for both the German and French models show that the validity is given. The loadings are all above the target value of 0.7 , and can therefore explain more than 50 percent of the variance of the latent construct. For the French-speaking group, the third indicator is below $0.7(0.632)$ and would there- fore usually be omitted. However, in order to keep the models comparable and due to the other quality criteria, which suggest that it is nonetheless a good model, this indicator will be kept.

In order to analyze the external validity of the formative model, the correlation of the formative indicators with a reflective indicator of the same construct will be examined. Therefore, a global item for each construct has been developed and was integrated in the survey (Buhmann \& Ingenhoff, 2015b). For the German-speaking part, all indicators show a significant positive correlation with the global item. For the French-speaking part, one indicator of the aesthetic dimension is not significantly correlated. Nevertheless, the great majority confirm the external validity of the constructs. In a next step, the model has to be tested for collinearity issues. The variance inflation factor (VIF) describes the "degree to which the standard error has been increased due to the presence of collinearity" (Hair Jr, Hult, Ringle, \& Sarstedt, 2013, pp. 124-125). In a PLS-SEM, a VIF-value $\geq 5$ implies collinearity issues. The VIF of the two models are all below the critical value. Therefore, we can assume that there are no collinearity issues within the models. In a final step, due to its significance and relevance, i.e. the outer weights, the functional item influential culture was omitted. From a theoretical point of view, it can be argued that a distinction from the aesthetic construct is difficult and that it might not be as important to the subjects in their functional country identity. The other indicators proved to be important.

To assess the structural model, the path coefficients and their $t$-values are examined in order to evaluate their significance. The cognitive components (as predicted by Buhmann and Ingenhoff, 2015a) all have a significant positive correlation with the affective component. The results of the $t$-values show that the cognitive dimensions contribute significantly in explaining the affective dimension, as they are all above the critical value of 1.96. The cognitive components explain $41.6 \%$ (German-speaking Swiss) to $67.2 \%$ (French-speaking Swiss) of the variance 
of the affective component. These results are satisfactory. For the German-speaking Swiss model all effect sizes are small, while for the French-speaking Swiss the $f^{2}$-effect size of the aesthetic construct is medium (Cohen, 2013). This means that for French-speaking Swiss the aesthetic dimension contributes more of the variance of the emotional dimension.

Although Tenenhaus, Amato, and Esposito Vinzi (2004) suggested a PLS goodness-of-fit (GoF) index, which would validate the model more globally, Henseler and Sarstedt (2013) came to the conclusion that the usefulness of the GoF is not given as a PLS-SEM criterion. The only approximate criterion to evaluate the model fit in PLS-SEM is the standardized root mean square residual (SRMR). The SRMR is the distance between the "model implied and the empirical correlation matrix" (Henseler, Hubona, \& Ray, 2016, p. 11). For the SRMR, a value of 0.08 or lower indicates a good model fit (Hu \& Bentler, 1999). The German-speaking Swiss model value is 0.055 and the French-speaking Swiss model value is 0.069 . Both models therefore show acceptable model fits.

In summary, the structural model results show two acceptable models (Figure 1 and 2), which sufficiently explain the variance of the endogenous construct and show significant paths. The SRMR indicates that both models have an acceptable fit, and are therefore ready for comparisons.

\subsection{Testing the hypothesis}

To test the first hypothesis, a Partial Least Squares Multi-Group Analysis (PLS-MGA) is conducted. The MGA aims to examine the effect of a categorical variable on the relationships of the PLS-SEM. This method offers the possibility of comparing the path model between the groups and evaluates the probability that parameter estimates are higher in one subsample than the other, in order to verify the probable difference of these estimates among the subgroups.

The first hypothesis states that the German-speaking Swiss have a different country identity to the French-speaking
Swiss. In order to examine this hypothesis an MGA between the German- and French-speaking groups is conducted including only the control group.

The results in Table 1 show that the German-speaking Swiss have a much higher coefficient for the relation between the normative and emotional constructs (0.318 to 0.072 ), while the French-speaking Swiss have higher coefficients for the relation between the functional and emotional ones (0.482 to 0.277$)$.

Table 2 presents the differences of the outer weights and loadings. Looking at the functional indicators it can be observed that the different language regions estimate the indicators very differently. For example, for the French-speaking Swiss the partialized effect of the country's innovativeness on the functional dimension is negative $(-0.317)$, whereas it is a high positive effect (0.204) for the German-speaking Swiss. The outer loadings (except for the fascination for Switzerland) all differ significantly. These results show that hypothesis 1 can be accepted. There are significant differences between the country identities of the two different language regions.

In order to analyze whether the public diplomacy strategies have an effect on country identity, the control group are compared with the treatment groups (Table 3). For the German-speaking Swiss no significant differences can be found. For the French-speaking Swiss there is a significant difference in relationship between the normative and emotional dimensions of the construct ( 0.062 to 0.282 ). Thus reading any of the three different frames seems to have an influence on the relationship between the normative and emotional dimensions of their country identity.

The differences between the indicators for the German-speaking Swiss can be seen in Table 4 . The results show that while the examination of the path differences showed no significant results for the German-speaking Swiss between those who were not exposed to a stimulus and those who were, the indicators differ between the groups. It is interesting to see 
Figure 1: Structural model results of the German-speaking group

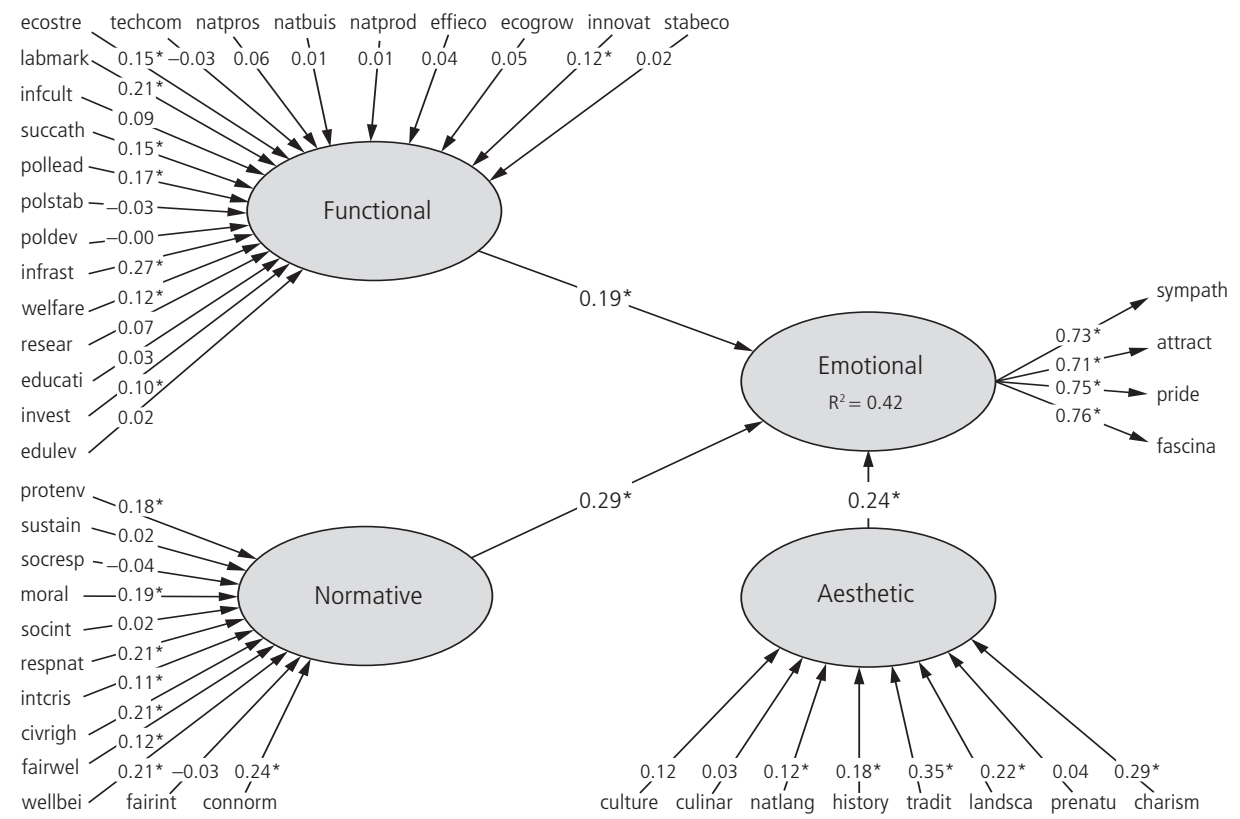

Note. German-speaking part of Switzerland ( $N=1218$ ); SRMR= 0.055; VIF: Functional =3.95, Normative 3.49; Aesthetic $=1.92 ;$ AVE: Emotion$\mathrm{al}=0.543$; Composite Reliability $=.826$; Cronbach's $\alpha=.720$; Bootstrapping $=5000$.

Figure 2: Structural model results of the French-speaking group

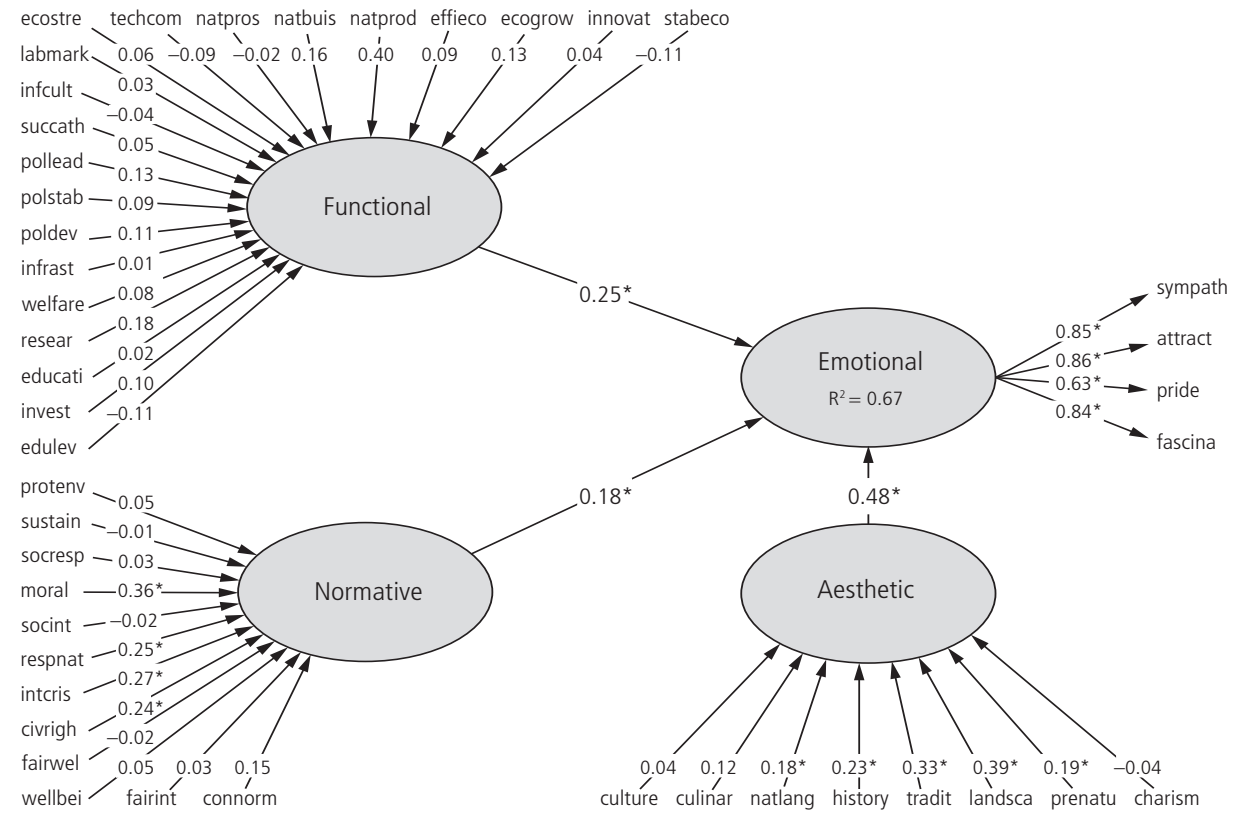

Note. French-speaking part of Switzerland $(n=259)$; SRMR=0.069; VIF: Functional=2.97, Normative=2.64; Aesthetic=2.18; AVE: Emotional $=0.640$; Composite Reliability $=.875$; Cronbach's $\alpha=.81$; Bootstrapping $=5000$. 
Table 1: Comparison of country identity in German- and French-speaking Switzerland

\begin{tabular}{l|ccc|ccc|c}
\hline & \multicolumn{3}{|c|}{ German-speaking $(n=311)$} & \multicolumn{3}{c|}{ French-speaking $(n=84)$} & \\
& Path coeff. & $t$-values & $S E$ & Path coeff. & $t$-values & $S E$ & $\mid$ diff $\mid$ \\
\hline FUNC $\rightarrow$ EMOT & 0.277 & 3.820 & 0.072 & 0.482 & 5.393 & 0.089 & $0.205^{*}$ \\
NORM $\rightarrow$ EMOT & 0.318 & 4.109 & 0.077 & 0.072 & 0.954 & 0.075 & $0.246^{*}$ \\
AESTH $\rightarrow$ EMOT & 0.167 & 2.643 & 0.063 & 0.380 & 4.696 & 0.081 & 0.213 \\
\hline
\end{tabular}

Note. ${ }^{*} p \leq .05 ;{ }^{* *} p \leq .01$.

Table 2: $\quad$ MGA results of comparison: Outer weights and loadings of the different language regions

\begin{tabular}{|c|c|c|c|c|c|c|c|}
\hline & \multicolumn{3}{|c|}{ German-speaking Switzerland } & \multicolumn{3}{|c|}{ French-speaking Switzerland } & \multirow[b]{2}{*}{$\mid$ diff $\mid$} \\
\hline & Loadings & $t$-values & $S E$ & Loadings & $t$-values & $S E$ & \\
\hline Liking the country & 0.722 & 15.816 & 0.046 & 0.883 & 24.445 & 0.036 & $0.161^{* *}$ \\
\hline Country attractiveness & 0.715 & 14.991 & 0.048 & 0.881 & 30.921 & 0.028 & $0.166^{* *}$ \\
\hline Pride in the country & 0.803 & 24.914 & 0.032 & 0.564 & 4.531 & 0.124 & $0.239 *$ \\
\hline Dimensions & Weights & $t$-values & $S E$ & Weights & $t$-values & SE & |diff $\mid$ \\
\hline \multicolumn{8}{|l|}{ Functional dimension } \\
\hline Country innovativeness & 0.204 & 1.767 & 0.116 & -0.317 & 1.919 & 0.165 & $0.521^{* *}$ \\
\hline Efficient economy & 0.100 & 1.058 & 0.095 & 0.612 & 2.833 & 0.216 & $0.511^{*}$ \\
\hline Economic strength & 0.180 & 2.070 & 0.087 & -0.092 & 0.686 & 0.134 & $0.272^{*}$ \\
\hline Use of international political developments & -0.228 & 1.745 & 0.131 & 0.311 & 2.035 & 0.153 & $0.539 * *$ \\
\hline Infrastructure & -0.009 & 0.097 & 0.097 & -0.360 & 2.154 & 0.167 & $0.351^{*}$ \\
\hline \multicolumn{8}{|l|}{ Normative dimension } \\
\hline Interest in well-being of fellow men & 0.320 & 2.606 & 0.123 & -0.089 & 0.419 & 0.211 & $0.213^{*}$ \\
\hline \multicolumn{8}{|l|}{ Aesthetic dimension } \\
\hline Culinary & 0.166 & 9.956 & 0.017 & 0.275 & 7.996 & 0.034 & $0.109^{* *}$ \\
\hline History & 0.161 & 8.304 & 0.019 & 0.082 & 1.410 & 0.058 & $0.116^{* *}$ \\
\hline Intact nature & 0.119 & 5.015 & 0.024 & 0.213 & 4.546 & 0.047 & $0.094^{*}$ \\
\hline Charismatic pers. & 0.224 & 10.595 & 0.021 & 0.094 & 2.079 & 0.045 & $0.130^{* *}$ \\
\hline
\end{tabular}

Note. ${ }^{*} p \leq .05 ;{ }^{* *} p \leq .01$. Table only contains on significant differences for readability reasons.

Table 3: Effects of stimuli on country identity of German- and French-speaking respondents

\begin{tabular}{|c|c|c|c|c|c|c|c|c|c|}
\hline \multicolumn{3}{|c|}{ German-speaking } & \multicolumn{3}{|c|}{ Control group: German-speaking ( $n=311$ ) } & \multicolumn{2}{|c|}{ Stimulus group: German-speaking $(n=907)$} & $\begin{array}{c}S E \\
(n=907)\end{array}$ & |diff $\mid$ \\
\hline FUNC & $\rightarrow$ & EMOT & 0.246 & 3.288 & 0.075 & 0.199 & 4.076 & 0.048 & 0.047 \\
\hline NORM & $\rightarrow$ & EMOT & 0.307 & 3.941 & 0.078 & 0.280 & 6.283 & 0.045 & 0.028 \\
\hline $\begin{array}{l}\text { AESTH } \\
\text { French-s }\end{array}$ & $\rightarrow$ & EMOT & $\begin{array}{l}0.221 \\
\text { Contro } \\
\end{array}$ & $\begin{array}{l}3.063 \\
\text { French-s }\end{array}$ & $\begin{array}{l}0.072 \\
n=84)\end{array}$ & $\begin{array}{l}0.242 \\
\text { Stimulus }\end{array}$ & $\begin{array}{l}5.575 \\
\text { French-s }\end{array}$ & $\begin{array}{l}0.043 \\
n=175)\end{array}$ & 0.021 \\
\hline FUNC & $\rightarrow$ & EMOT & 0.460 & 5.101 & 0.089 & 0.249 & 3.305 & 0.075 & $0.211^{*}$ \\
\hline NORM & $\rightarrow$ & EMOT & 0.062 & 0.771 & 0.080 & 0.282 & 4.072 & 0.069 & $0.220^{*}$ \\
\hline AESTH & $\rightarrow$ & EMOT & 0.422 & 5.237 & 0.081 & 0.395 & 5.288 & 0.075 & 0.027 \\
\hline
\end{tabular}

Note. ${ }^{*} p \leq .05 ;{ }^{* *} p \leq .01$. 
Table 4: $\quad$ MGA results of comparison: Outer weights and loadings of German-speaking respondents with and without Stimulus

\begin{tabular}{|c|c|c|c|c|c|c|c|}
\hline & \multicolumn{3}{|c|}{ Control group } & \multicolumn{3}{|c|}{ Stimulus group } & \multirow[b]{2}{*}{$\mid$ diff $\mid$} \\
\hline & Loadings & $t$-values & SE & Loadings & $t$-values & $S E$ & \\
\hline Pride in the country & 0.804 & 24.991 & 0.032 & 0.727 & 27.044 & 0.027 & $0.077^{*}$ \\
\hline Dimensions & Weights & $t$-values & $S E$ & Weights & $t$-values & $S E$ & |diff $\mid$ \\
\hline \multicolumn{8}{|l|}{ Functional dimension } \\
\hline Efficient economy & 0.219 & 1.978 & 0.111 & -0.040 & 0.685 & 0.058 & $0.259^{*}$ \\
\hline Use of international political developments & -0.008 & 0.088 & 0.095 & 0.262 & 4.149 & 0.063 & $0.270^{* *}$ \\
\hline Infrastructure & -0.227 & 1.718 & 0.132 & 0.031 & 0.390 & 0.081 & $0.259^{*}$ \\
\hline \multicolumn{8}{|l|}{ Normative dimension } \\
\hline Environmental protection & 0.350 & 3.127 & 0.112 & 0.099 & 1.540 & 0.064 & $0.251^{*}$ \\
\hline Sustainability & -0.229 & 2.590 & 0.088 & 0.134 & 2.483 & 0.054 & $0.363^{* *}$ \\
\hline High moral standards & 0.317 & 3.235 & 0.098 & 0.127 & 2.223 & 0.057 & $0.191^{*}$ \\
\hline Fair welfare system & -0.031 & 0.273 & 0.112 & 0.182 & 2.880 & 0.063 & $0.213^{*}$ \\
\hline \multicolumn{8}{|l|}{ Aesthetic dimension } \\
\hline Cultural goods & -0.058 & 0.449 & 0.128 & 0.186 & 2.434 & 0.076 & $0.244^{* *}$ \\
\hline Landscape & -0.066 & 0.514 & 0.127 & 0.336 & 4.516 & 0.074 & $0.402^{*}$ \\
\hline
\end{tabular}

Note. ${ }^{*} p \leq .05 ;{ }^{* *} p \leq .01$

that there are indicators that have higher effects, while others have lower effects among the functional and normative dimensions when exposed to the stimuli. However, the significant differences of the aesthetic indicators are all higher when the subjects read a stimulus.

For the French-speaking Swiss, the indicators of the emotional dimension do not show any significant difference between the group with a stimulus and the control group (Table 5). It can be seen that the indicators of the functional dimension reacted the most with the stimuli. Overall the results show differences between the group with a stimulus and the group without, either in the paths or the indicators or both. Therefore, the second hypothesis can be confirmed. There is a difference in country identity after being exposed to a stimulus.

Hypothesis 3 states that the recipients' personal beliefs on the communicated issue of the public diplomacy message moderates the effect that the message has on their country identity. Even though there were differently-framed messages, they were all explaining the acceptance of the yes vote in a subjective way. This means that the personal beliefs of the supporters of the mass immigration initiative (i.e. their acceptance) were reflected in the text. Thus, the same analysis as before is conducted again, but this time with the two language regions further separated in their personal beliefs on the mass immigration initiative (i.e. supporters and opponents).

In Table 6 the results of the combined calculation are presented. The results show that within the German-speaking Swiss only the supporters of the mass immigration initiative show a significant difference between the group with the stimuli and the group without. The different path is the one between the functional and emotional construct, which is higher when exposed to a stimulus (0.178 to 0.303 ). Interestingly, for the French-speaking supporters this result cannot be observed. However, there might still be differences found among the indicators of the different subgroups. Tables 7, 8 and 9 present the multi-group analysis results for the indicator weights and loadings for the different subgroups calculated in Table 6 .

For the German-speaking Swiss who support the mass immigration initiative, the results show that for the normative and aesthetic dimensions the effects are significantly higher when exposed to the stimuli. However, the functional dimen- 
Table 5: $\quad$ MGA results of comparison: Outer weights and loadings of French-speaking respondents with and without stimulus

\begin{tabular}{l|ccc|ccc|c}
\hline Dimensions & \multicolumn{3}{|c|}{ Control group } & \multicolumn{3}{c|}{ Stimulus group } & \\
& Weights & $t$-values & $S E$ & Weights & $t$-values & $S E$ & $\mid$ diff $\mid$ \\
\hline Functional dimension & & & & & & & \\
Country innovativeness & -0.318 & 1.917 & 0.166 & 0.076 & 0.839 & 0.090 & $0.394^{*}$ \\
Efficient economy & 0.613 & 2.867 & 0.214 & -0.114 & 0.762 & 0.149 & $0.726^{* *}$ \\
Use of international political developments & 0.312 & 2.082 & 0.150 & 0.005 & 0.059 & 0.090 & $0.306^{*}$ \\
Infrastructure & -0.361 & 2.158 & 0.167 & 0.282 & 2.559 & 0.110 & $0.642^{* *}$ \\
Normative dimension & & & & & & & \\
Environmental protection & 0.326 & 1.842 & 0.177 & -0.137 & 1.441 & 0.095 & $0.463^{* *}$ \\
\hline
\end{tabular}

Note. ${ }^{*} p \leq .05 ;{ }^{* *} p \leq .01$.

Table 6: Effects of stimuli on country identity of German- and French-speaking respondents with regard to political beliefs

\begin{tabular}{|c|c|c|c|c|c|c|c|c|c|}
\hline & & & Path coeff. & $t$-value & $S E$ & Path coeff. & $t$-values & $S E$ & $\mid$ diff $\mid$ \\
\hline \multicolumn{10}{|c|}{ German speaking } \\
\hline & & & \multicolumn{3}{|c|}{ Control group: Supporter $(n=219)$} & \multicolumn{3}{|c|}{ Stimulus group: Supporter $(n=626)$} & \\
\hline FUNC & $\rightarrow$ & EMOT & 0.403 & 2.535 & 0.077 & 0.142 & 6.025 & 0.055 & $0.262^{*}$ \\
\hline NORM & $\rightarrow$ & EMOT & 0.178 & 5.264 & 0.070 & 0.303 & 2.599 & 0.050 & 0.125 \\
\hline \multirow[t]{2}{*}{ AESTH } & \multirow{2}{*}{\multicolumn{2}{|c|}{$\rightarrow \quad$ EMOT }} & 0.255 & 3.714 & 0.069 & 0.274 & 5.150 & 0.053 & 0.019 \\
\hline & & & \multicolumn{3}{|c|}{ Control group: Opponents ( $n=78)$} & \multicolumn{3}{|c|}{ Stimulus group: Opponents $(n=241)$} & \\
\hline FUNC & $\rightarrow$ & EMOT & 0.447 & 3.362 & 0.133 & 0.315 & 3.886 & 0.081 & 0.131 \\
\hline NORM & $\rightarrow$ & EMOT & 0.295 & 2.728 & 0.108 & 0.232 & 3.128 & 0.074 & 0.063 \\
\hline AESTH & $\rightarrow$ & EMOT & 0.218 & 2.217 & 0.098 & 0.233 & 3.258 & 0.071 & 0.015 \\
\hline \multicolumn{10}{|c|}{ French-speaking Swiss } \\
\hline & & & \multicolumn{3}{|c|}{ Control group: Supporter $(n=54)$} & \multicolumn{3}{|c|}{ Stimulus group: Supporter $(n=103)$} & \\
\hline FUNC & $\rightarrow$ & EMOT & 0.497 & 4.102 & 0.121 & 0.492 & 5.771 & 0.085 & 0.004 \\
\hline NORM & $\rightarrow$ & EMOT & 0.112 & 1.150 & 0.098 & 0.123 & 1.677 & 0.077 & 0.011 \\
\hline AESTH & $\rightarrow$ & EMOT & 0.326 & 3.307 & 0.099 & 0.348 & 4.511 & 0.077 & 0.022 \\
\hline
\end{tabular}

Note. ${ }^{*} p \leq .05 ;{ }^{* *} p \leq .01$.

Table 7: $\quad$ MGA results of comparison: Outer weights and loadings of German-speaking respondents with and without stimulus moderated by supporting (congruent) personal beliefs

\begin{tabular}{l|ccc|ccc|c}
\hline & \multicolumn{5}{|c|}{ Control group } & \multicolumn{3}{c}{ Stimulus group } & \\
& Loadings & $t$-values & $S E$ & Loadings & $t$-values & $S E$ & $\mid$ diff $\mid$ \\
\hline Pride in the country & 0.810 & 23.102 & 0.035 & 0.713 & 20.283 & 0.035 & $0.097^{*}$ \\
& Weights & $t$-values & $S E$ & Weights & $t$-values & $S E$ & $\mid$ diff $\mid$ \\
\hline Functional dimension & & & & & & & \\
Stable economic system & -0.105 & 1.259 & 0.084 & 0.099 & 1.296 & 0.076 & $0.204^{*}$ \\
Country innovativeness & 0.390 & 3.449 & 0.113 & 0.118 & 1.291 & 0.091 & $0.272^{*}$ \\
Political stability & -0.080 & 0.821 & 0.098 & 0.315 & 3.761 & 0.084 & $0.396^{* *}$ \\
Normative dimension & & & & & & & \\
$\quad$ Sustainability & -0.194 & 1.921 & 0.101 & 0.130 & 1.912 & 0.068 & $0.324^{* *}$ \\
Fairness of international economic/trade policy \\
Aesthetic dimension & -0.132 & 1.291 & 0.103 & 0.090 & 1.223 & 0.074 & $0.223^{*}$ \\
Landscape & -0.165 & 1.334 & 0.124 & 0.313 & 3.169 & 0.099 & $0.478^{* *}$ \\
\hline
\end{tabular}

Note. ${ }^{*} p \leq .05 ;{ }^{* *} p \leq .01$. 
Table 8: $\quad$ MGA results of comparison: outer weights and loadings of German-speaking respondents with and without stimulus moderated by opposing (incongruent) opinion

\begin{tabular}{|c|c|c|c|c|c|c|c|}
\hline & \multicolumn{3}{|c|}{ Control group } & \multicolumn{3}{|c|}{ Stimulus group } & \multirow[b]{2}{*}{$\mid$ diff $\mid$} \\
\hline & Weights & $t$-values & SE & Weights & $t$-values & SE & \\
\hline \multicolumn{8}{|l|}{ Functional dimension } \\
\hline Use of international political developments & -0.471 & 1.672 & 0.282 & 0.091 & 0.883 & 0.103 & $0.562^{*}$ \\
\hline \multicolumn{8}{|l|}{ Normative dimension } \\
\hline Sustainability & -0.302 & 1.542 & 0.196 & 0.098 & 0.997 & 0.098 & $0.400^{*}$ \\
\hline Engagement for societal interests & 0.471 & 2.247 & 0.210 & 0.085 & 0.892 & 0.096 & $0.386^{*}$ \\
\hline Respect for other nations & -0.687 & 2.543 & 0.270 & 0.227 & 2.117 & 0.107 & $0.914^{* *}$ \\
\hline \multicolumn{8}{|l|}{ Aesthetic dimension } \\
\hline National languages & -0.350 & 1.300 & 0.269 & 0.177 & 1.243 & 0.143 & $0.528^{*}$ \\
\hline
\end{tabular}

Table 9: MGA Results of comparison: outer weights and loadings of French-speaking respondents with and without Stimulus moderated by supporting (congruent) personal beliefs

\begin{tabular}{|c|c|c|c|c|c|c|c|}
\hline & \multicolumn{3}{|c|}{ Control group } & \multicolumn{3}{|c|}{ Stimulus group } & \multirow[b]{2}{*}{ |diff $\mid$} \\
\hline & Loadings & $t$-values & $S E$ & Loadings & $t$-values & $S E$ & \\
\hline \multirow[t]{2}{*}{ Pride in the country } & 0.220 & 1.077 & 0.204 & 0.675 & 9.573 & 0.071 & $0.455^{*}$ \\
\hline & Weights & $t$-values & $S E$ & Weights & $t$-values & SE & |diff $\mid$ \\
\hline \multicolumn{8}{|l|}{ Functional dimension } \\
\hline Country innovativeness & -0.559 & 2.008 & 0.278 & 0.129 & 1.196 & 0.108 & $0.688^{*}$ \\
\hline Successful athletes & 0.287 & 1.254 & 0.229 & -0.177 & 1.687 & 0.105 & $0.463^{*}$ \\
\hline Infrastructure & -0.623 & 1.617 & 0.385 & 0.201 & 1.663 & 0.121 & $0.825^{*}$ \\
\hline \multicolumn{8}{|l|}{ Normative dimension } \\
\hline Environmental protection & 0.481 & 1.994 & 0.241 & -0.168 & 1.348 & 0.125 & $0.649 *$ \\
\hline \multicolumn{8}{|l|}{ Aesthetic dimension } \\
\hline Intact nature & 0.472 & 2.743 & 0.172 & 0.091 & 0.941 & 0.097 & $0.381^{*}$ \\
\hline
\end{tabular}

Note. ${ }^{*} p \leq 0.05 ;{ }^{* *} p \leq 0.01$.

sion offers mixed differences (higher and lower for the group with the stimuli). It is also interesting that pride in the country has a lower effect when exposed to the stimulus.

For the German-speaking Swiss who opposed the initiative it can be seen that none of the emotional indicators are significantly affected by the stimulus. Except for one indicator (engagement for societal interests 0.471 to 0.085 ), all indicators have higher effects on the different dimensions.

For the French-speaking Swiss who supported the mass immigration initiative, as with the German-speaking supporters, the indicator "pride in the country" is lower when exposed to the stimulus. But the values of the loadings are way below the critical value of 0.7 . Therefore this indicator does not reflect the favor- able attitude towards the country of the French-speaking Swiss who supported the mass immigration initiative. However, in contrast to the German-speaking supporters, the normative and aesthetic indicators with significant differences are lower $(0.481$ to $-0.168 ; 0.472$ to 0.091$)$ for the French-speaking Swiss when exposed to the stimulus. Here, the functional indicators again offer mixed significant differences. Unfortunately, the French-speaking Swiss group who oppose the mass immigration initiative is too small (i.e. $n=28$ in the control group) to get any valid results. Therefore, this space is left blank in the Table 6.

These results show that personal beliefs on the issue are actually moderating the effect of public diplomacy on country 
identity. Thus, hypothesis 3 can be accepted.

The final hypothesis states that differently-framed public diplomacy messages have different effects on country identity. Therefore, the separate treatment groups and the control group will be compared to evaluate the varying reactions to differently-framed public diplomacy communication. Tables 10 and 11 show the comparisons between the different experimental groups. The results show that for the German-speaking Swiss the groups do not differ significantly among the paths. Thus, there is no difference between the subjects who were exposed to a functional framed stimulus, a normative framed stimulus, an aesthetic framed stimulus or even none at all on the paths. However, previous results of this study confirmed the moderating role of personal beliefs on the issue, which means that it is possible that political beliefs moderate the effect again here.

For the French-speaking Swiss the results show a different picture. Comparing the control group with the group that had a functional framed stimulus, the path between the normative and the emotional construct exhibits a significant difference. This path increases ( 0.062 to 0.233 ) when the subjects are exposed to a functional framed message. The same is true for the comparison between the control group and the group with the normative framed stimulus, as the path between the normative and emotional constructs increases by 0.189 (0.062 to 0.251$)$. There is also a significant difference between the control group and the group with the normative framed stimulus with the path between

Table 10: Multi-group analysis of all treatment groups: Comparison of the effects of the different frames on country identity of German-speaking respondents

\begin{tabular}{|c|c|c|c|c|c|c|c|c|c|c|c|c|c|c|}
\hline \multirow{2}{*}{\multicolumn{3}{|c|}{ Relations }} & \multicolumn{3}{|c|}{$\begin{array}{c}\text { Control group } \\
(n=311)\end{array}$} & \multicolumn{3}{|c|}{$\begin{array}{l}\text { Functional framed } \\
\qquad(n=322)\end{array}$} & \multicolumn{3}{|c|}{$\begin{array}{l}\text { Normative framed } \\
\quad(n=278)\end{array}$} & \multicolumn{3}{|c|}{$\begin{array}{l}\text { Aesthetic framed } \\
\quad(n=307)\end{array}$} \\
\hline & & & Path coeff & $\mathrm{t}$-values & SE & Path coeff & t-values & SE & Path coeff & f. t-values & SE & Path coeff & t-values & SE \\
\hline$\overline{\text { FUNC }}$ & $\rightarrow$ & EMOT & 0.246 & 3.262 & 0.075 & 0.278 & 4.216 & 0.066 & 0.313 & 3.851 & 0.065 & 0.313 & 4.585 & 0.068 \\
\hline NORM & $\rightarrow$ & EMOT & 0.307 & 3.836 & 0.080 & 0.204 & 3.039 & 0.067 & 0.239 & 3.691 & 0.081 & 0.299 & 4.767 & 0.063 \\
\hline AESTH & $\rightarrow$ & EMOT & 0.221 & 3.084 & 0.072 & 0.276 & 4.262 & 0.065 & 0.241 & 3.478 & 0.069 & 0.151 & 2.250 & 0.067 \\
\hline
\end{tabular}

Differences (MGA)

\begin{tabular}{|c|c|c|c|c|c|c|c|c|c|}
\hline \multicolumn{4}{|c|}{ Relations } & $\mathrm{CG} \rightarrow \mathrm{TG}_{\mathrm{F}}$ & $\mathrm{CG} \rightarrow \mathrm{TG}_{\mathrm{N}}$ & $\mathrm{CG} \rightarrow \mathrm{TG}_{\mathrm{A}}$ & $\mathrm{TG}_{\mathrm{F}} \rightarrow \mathrm{TG}_{\mathrm{N}}$ & $\mathrm{TG}_{\mathrm{F}} \rightarrow \mathrm{TG}_{\mathrm{A}}$ & $\mathrm{TG}_{\mathrm{N}} \rightarrow \mathrm{TG}_{\mathrm{A}}$ \\
\hline \multirow{3}{*}{ 雱 } & FUNC & $\rightarrow$ & EMOT & 0.032 & 0.067 & 0.067 & 0.035 & 0.035 & 0.000 \\
\hline & NORM & $\rightarrow$ & EMOT & 0.103 & 0.068 & 0.009 & 0.035 & 0.095 & 0.060 \\
\hline & AESTH & $\rightarrow$ & EMOT & 0.055 & 0.020 & 0.070 & 0.035 & 0.125 & 0.090 \\
\hline
\end{tabular}

Note. ${ }^{*} p \leq 0.05 ;{ }^{* *} p \leq 0.01$.

Table 11: Multi-group analysis of all treatment groups: Comparison of the effects of the different frames on country identity of French-speaking respondents

\begin{tabular}{|c|c|c|c|c|c|c|c|c|c|c|c|c|c|c|}
\hline \multicolumn{3}{|c|}{ Relations } & \multicolumn{3}{|c|}{ Control group $(n=84)$} & \multicolumn{3}{|c|}{ Functional framed $(n=44)$} & \multicolumn{3}{|c|}{ Normative framed $(n=65)$} & \multicolumn{3}{|c|}{ Aesthetic framed $(n=66)$} \\
\hline & & & Path coeff. & $t$-values & SE & Path coeff. & $t$-values & SE & Path coeff. & $t$-values & SE & Path coeff. & $t$-values & $S E$ \\
\hline FUNC & $\rightarrow$ & EMOT & 0.460 & 5.154 & 0.089 & 0.393 & 2.496 & 0.091 & 509 & 3.740 & 0.136 & 0.311 & 2.669 & 0.116 \\
\hline NORM & $\rightarrow$ & EMOT & 62 & 0.782 & 0.079 & 0.233 & 2.563 & 0.157 & 0.251 & 2.230 & 0.112 & 0.214 & 2.310 & 0.093 \\
\hline ESTH & $\rightarrow$ & EMOT & 0.422 & 5.195 & 0.081 & 0.396 & 3.463 & 0.114 & 0.178 & 1.664 & 0.107 & 0.446 & 4.046 & 0.1 \\
\hline
\end{tabular}

Differences (MGA)

\begin{tabular}{|c|c|c|c|c|c|c|c|c|c|}
\hline \multicolumn{4}{|c|}{ Relations } & \multirow{2}{*}{$\begin{array}{c}\mathrm{CG} \rightarrow \mathrm{TG}_{\mathrm{F}} \\
0.067\end{array}$} & \multirow{2}{*}{$\begin{array}{c}\mathrm{CG} \rightarrow \mathrm{TG}_{\mathrm{N}} \\
0.049\end{array}$} & \multirow{2}{*}{$\begin{array}{c}\mathrm{CG} \rightarrow \mathrm{TG}_{\mathrm{A}} \\
0.149\end{array}$} & \multirow{2}{*}{$\begin{array}{c}\mathrm{TG}_{\mathrm{F}} \rightarrow \mathrm{TG}_{\mathrm{N}} \\
0.116\end{array}$} & \multirow{2}{*}{$\begin{array}{c}\mathrm{TG}_{\mathrm{F}} \rightarrow \mathrm{TG}_{\mathrm{A}} \\
0.082\end{array}$} & \multirow{2}{*}{$\begin{array}{c}\mathrm{TG}_{\mathrm{N}} \rightarrow \mathrm{TG} \\
0.198\end{array}$} \\
\hline \multirow{3}{*}{ 䨌 } & FUNC & $\rightarrow$ & EMOT & & & & & & \\
\hline & NORM & $\rightarrow$ & EMOT & $0.172^{*}$ & $0.189^{*}$ & 0.152 & 0.017 & 0.020 & 0.037 \\
\hline & AESTH & $\rightarrow$ & EMOT & 0.026 & $0.245^{* *}$ & 0.024 & $0.218^{*}$ & 0.050 & $0.269^{* *}$ \\
\hline
\end{tabular}

Note. ${ }^{*} p \leq 0.05 ;{ }^{* *} p \leq 0.01$. 
the aesthetic and the emotional construct (0.422 to 0.178$)$. Thus, the path decreases significantly if the subjects are exposed to the normative framed stimulus. Another significant difference occurs between the group with the functional framed article and those with the normative framed article. The path between the aesthetic and the emotional construct is lower $(0.396$ to 0.178 ) if a normative framed article was read in comparison with the functional framed article. Also, a significant difference can be seen between the group with the normative frame and the one with the aesthetic frame. The differing path is again the one between the aesthetic and the emotional construct ( 0.178 to 0.446$)$, which is higher with the aesthetic framed stimulus compared to the normative framed stimulus. Thus, there is a different effect on the country identity of the French-speaking Swiss subjects depending on how a public diplomacy message is framed.
Unfortunately, for the French-speaking Swiss, separating the groups into four subgroups again makes it impossible to check for the moderating effect of political beliefs because the groups are too small (i.e., $n=28 \mathrm{CG} ; n=16 \mathrm{TG}_{\mathrm{N}} ; n=26 \mathrm{TG}_{\mathrm{F}}$; $\left.n=25 \mathrm{TG}_{\mathrm{A}}\right)$. Therefore, this step can only be made for the German-speaking Swiss. The results show significant differences for the German-speaking Swiss who support the mass immigration initiative. Table 12 displays the results of the comparison. It can be seen that there are significant differences between the control group and the other groups. Between the control group and the group with the functional stimulus, the path between the functional dimension and the emotional dimension differs significantly. Looking at the path coefficients it can be observed that the control group's path is higher than the functional framed group's (0.403 to 0.219 ). But the control group also differs from the other two dimensions regarding the path

Table 12: Multi-group analysis of all treatment groups: Comparison of the effects of the different frames on country identity of German-speaking respondents controlled for political beliefs

\begin{tabular}{|c|c|c|c|c|c|c|c|c|c|c|c|c|c|c|}
\hline \multirow{2}{*}{\multicolumn{3}{|c|}{ Relations }} & \multicolumn{3}{|c|}{ Control group } & \multicolumn{3}{|c|}{ Functional framed } & \multicolumn{3}{|c|}{ Normative framed } & \multicolumn{3}{|c|}{ Aesthetic framed } \\
\hline & & & \multicolumn{2}{|c|}{ Path coeff. $t$-values } & \multirow[t]{2}{*}{$S E$} & \multicolumn{2}{|c|}{ Path coeff. $t$-values } & \multirow{2}{*}{ SE } & \multicolumn{2}{|c|}{ Path coeff. $t$-values } & \multirow[t]{2}{*}{ SE } & \multicolumn{2}{|c|}{ Path coeff. $t$-values } & \multirow[t]{2}{*}{$S E$} \\
\hline \multicolumn{11}{|c|}{ Supporters } & & & & \\
\hline FUNC & $\rightarrow$ & EMOT & 0.403 & 5.260 & 0.077 & 0.219 & 3.017 & 0.073 & 0.268 & 3.429 & 0.078 & 0.280 & 3.258 & 0.086 \\
\hline NORM & $\rightarrow$ & EMOT & 0.178 & 2.546 & 0.070 & 0.221 & 2.844 & 0.078 & 0.329 & 4.452 & 0.074 & 0.311 & 4.442 & 0.070 \\
\hline AESTH & $\rightarrow$ & EMOT & 0.225 & 3.672 & 0.069 & 0.308 & 4.207 & 0.073 & 0.213 & 2.998 & 0.071 & 0.156 & 1.752 & 0.089 \\
\hline \multicolumn{15}{|c|}{ Opponents } \\
\hline FUNC & $\rightarrow$ & EMOT & 0.447 & 3.378 & 0.132 & 0.455 & 3.969 & 0.115 & 0.569 & 4.439 & 0.128 & 0.460 & 5.217 & 0.088 \\
\hline NORM & $\rightarrow$ & EMOT & 0.295 & 2.803 & 0.105 & 0.209 & 2.243 & 0.093 & 0.154 & 1.400 & 0.110 & 0.234 & 2.333 & 0.100 \\
\hline AESTH & $\rightarrow$ & EMOT & 0.218 & 2.124 & 0.103 & 0.142 & 1.668 & 0.085 & 0.213 & 1.951 & 0.109 & 0.196 & 2.205 & 0.089 \\
\hline
\end{tabular}

\begin{tabular}{|c|c|c|c|c|c|c|}
\hline Relations & $\mathrm{CG} \rightarrow \mathrm{TG}_{\mathrm{F}}$ & $\mathrm{CG} \rightarrow \mathrm{TG}_{\mathrm{N}}$ & $\mathrm{CG} \rightarrow \mathrm{TG}_{\mathrm{A}}$ & $\mathrm{TG}_{\mathrm{F}} \rightarrow \mathrm{TG}_{\mathrm{N}}$ & $\mathrm{TG}_{\mathrm{F}} \rightarrow \mathrm{TG}_{\mathrm{A}}$ & $\mathrm{TG}_{\mathrm{N}} \rightarrow \mathrm{TG}_{\mathrm{A}}$ \\
\hline \multicolumn{7}{|l|}{ Differences (MGA) } \\
\hline \multicolumn{7}{|c|}{ Supporters |diff| } \\
\hline FUNC $\rightarrow$ EMOT & $0.184^{* *}$ & 0.135 & 0.124 & 0.049 & 0.060 & 0.011 \\
\hline NORM $\rightarrow$ EMOT & 0.043 & $0.151^{*}$ & $0.133^{*}$ & 0.108 & 0.090 & 0.018 \\
\hline AESTH $\rightarrow$ EMOT & 0.053 & 0.042 & 0.099 & 0.095 & $0.152^{*}$ & 0.057 \\
\hline \multicolumn{7}{|c|}{ Opponents |diff| } \\
\hline FUNC $\rightarrow$ EMOT & 0.008 & 0.122 & 0.014 & 0.114 & 0.005 & 0.109 \\
\hline NORM $\rightarrow$ EMOT & 0.086 & 0.141 & 0.061 & 0.055 & 0.026 & 0.080 \\
\hline AESTH $\rightarrow$ EMOT & 0.076 & 0.005 & 0.022 & 0.070 & 0.053 & 0.017 \\
\hline
\end{tabular}


between the normative and the emotional dimension. Each group's path coefficient is significantly higher than that of the control group (0.178 to $0.329 ; 0.178$ to 0.311 ). Another group comparison that offers a significant difference is that between the functional framed group and the aesthetic framed group. The path coefficient between the aesthetic and the emotional construct is significantly higher for the group that was exposed to the functional framed newspaper article (0.308 to 0.156$)$. Thus, for both language groups there have been significant differences between the control group and at least one treatment group. Therefore, hypothesis 4 can be accepted. There is an effect of public diplomacy strategies on country identity.

\subsection{Interpretation}

The results indicate a clear difference between the country identities of the German-speaking and French-speaking Swiss. The composition of the different dimensions differs significantly between the two language regions, which confirms the findings of Smith (1995) that the different regions have different values, attitudes and, most importantly, identities. It is noticeable that for the French-speaking Swiss the normative dimension seems not to be a significant part of their constructed country identity, while it is the most important one for the German-speaking Swiss. This means that the German-speaking Swiss compose their country identity more from their beliefs about norms and values while the French-speaking Swiss have stronger beliefs about the competitiveness of Switzerland and the attractiveness of the Swiss culture and landscape.

Comparing the country identity of the groups who were not exposed to the stimulus with those who were, the results show significant differences. For the French-speaking Swiss these differences are immediately clear. Their normative dimension is more important after being exposed to the stimulus, which indicates that reading how the federal council explains the acceptance of the mass immigration initiative to foreign publics triggers the normative dimension, which then constitutes the favorable attitude toward their own country and with it their country identity. As the debate is an issue that concerns a lot of normative values (treatment of immigrants), it makes sense that this dimension is triggered by the messages overall. The increase of the normative dimension implies that the French-speaking Swiss value this dimension (i.e. the norms and values of Switzerland) more highly when they are exposed to a stimulus, even though this dimension did not contribute to their emotional attitude towards Switzerland before the stimulus. On the other hand, they perceive the competences and competitiveness as lower than they did without having read the newspaper article. These results suggest that what they have read intensified their beliefs about the normative attributes of Switzerland but also weakened their beliefs about the competitive attributes. This reflects the thought of Ajzen and Fishbein (1980) that "the purpose of persuasive communication is to change the primary beliefs [...]." For the German-speaking Swiss there is no difference in the relations of the dimensions of their country identity. However, looking at the indicator differences for the German-speaking Swiss also reveals significant changes as a result of the stimuli. Thus, for both language regions significant differences can be found between the subjects who were not exposed to a public diplomacy message and those who were. These results confirm the hypothesis that public diplomacy strategies do have an effect on the country identity of the domestic public.

Testing the same comparison as above, while using personal beliefs on the mass immigration initiative as a moderating variable, reveals significant differences in paths as well as indicators. The results show that for the German-speaking Swiss supporters the effect on congruent personal beliefs is verifiable, while looking at the paths none can be detected for the opponents. German-speaking supporters of the initiative who read a public diplomacy message estimated the competitiveness of Switzerland to be higher than those who were not exposed to the message. However, 
German-speaking opponents did not show any reaction to the stimulus. This finding is in line with the assumption of Entman (2008) that issues have stronger effects on recipients whose personal beliefs are congruent to the issue, than on incongruently-opinioned recipients. Interestingly, for the French-speaking Swiss who supported the initiative, no significant difference of the paths can be found. This is, insofar as it goes, not intuitive as previous results showed significant differences between French-speaking Swiss who were exposed to a stimulus and the control groups. However, looking again at the indicator differences, multiple changes of the country identity can be observed. Thus, the personal beliefs on the issue being communicated are clearly moderating the effects of public diplomacy on country identity. This means that the overall frame, i. e. whether an issue is communicated in a positive or negative way, does have a different effect depending on the recipients' personal beliefs. These results underline previous findings that a strong opinion or belief has an impact on the effect of frames (Druckman \& Nelson, 2003; Slothuus, 2008).

Also acting as moderators are the different frames used to design the public diplomacy messages. The German-speaking Swiss who supported the initiative show a significant difference between the control group and the other three groups. The control group's path between the functional and emotional constructs is significantly higher than that of the functional framed group, while its path between the normative and emotional constructs is significantly lower than that of the groups exposed to a normative or aesthetic framed stimulus. This means that the belief in the competitiveness of Switzerland declines when exposed to the functional framed public diplomacy messages. Thus, for supporters of the mass immigration initiative, the functional arguments for its acceptance, which were stated in the article, trigger a decline in the functional dimension of Switzerland. On the other hand, being exposed to a normative or aesthetic framed newspaper article triggered an increase of belief in the norms and values of Switzerland. Another significant difference can be seen between the functional framed stimulus group and the aesthetic framed stimulus group. The belief in the attractiveness and beauty of Switzerland's culture and landscapes is significantly lower when the subjects were exposed to the aesthetic frame than to the functional frame. This could imply that the supporters might have feared the loss of cultivated land, which was mentioned in the aesthetic framed article. Considering their profession as farmers, this issue might have had a stronger effect. The results for the French-speaking Swiss show firstly that there is a significant difference between the control group and the groups with the functional and normative framed newspaper articles. Both groups with stimuli show an increase in the path of the normative to the emotional construct. This result reflects what has been observed before while testing all treatment groups combined. Thus, reading how the federal council explains the acceptance of the mass immigration initiative by referring to one of these two dimensions triggers an increase in the beliefs of the French-speaking Swiss about the normative dimension of Switzerland. There is also a significant difference on the path between the aesthetic and the emotional construct between the normative framed stimulus group and all the other groups. The results show a significant decrease of that path within the group with the normative framed newspaper article compared to all other groups. This indicates that, compared to all other groups, having read the normative framed article the subjects' beliefs about the beauty of Switzerland's culture, tradition and landscapes is much lower. At first glance this result is counterintuitive as it is not clear why the normative frame affects the aesthetic beliefs regarding the country identity of the French-speaking Swiss. However, the structural model results identified a much larger $f^{2}$-effect size for the aesthetic construct than for either of the other two. Therefore, it can be assumed that the country identity of the French-speaking Swiss depends very strongly on their 
aesthetic beliefs about the country. These results show that depending on what is communicated and what is not, different effects can be observed. In the case of the mass immigration initiative, communicating the arguments from different perspectives changed the country identity of the domestic public in different ways. Thus, it is not only what is said that is important, but also in what overall tone and in what perspectives it is framed. Additionally, the country identity composition (i.e. what dimensions are important and to what extent) plays a role on the effect (direction and intensiveness) of the public diplomacy message on the country identity.

\section{Discussion and conclusion}

The aim of this study was to analyze the effect of differently-framed public diplomacy messages on the domestic public's country identity. The assumption behind this analysis is that, due to globalization and digitalization, publics in the digital era are interconnected and information can be accessed around the globe. Thus, public diplomacy messages which might originally be designed to alter a foreign public's image of a country can also be received by the domestic public and potentially alter their country identity. Applied to a country like Switzerland, with its different language regions, different country identities within a country should not be ignored. As Anthony D. Smith (1986, p. 220) states: "language as a criterion of the 'genuine' nation has erected new barriers within and outside the community. [...] Language introduces a new powerful dimension of identification and community, but it also becomes a [...] new principle of cleavage and antagonism, superimposed on other cultural differences." Therefore, this study examined the different country identities of the two biggest language regions of Switzerland and the effect of differently-framed public diplomacy messages on these country identities. An experimental design study was conducted to analyze the causal relationships between the public diplomacy messages and the country identity, which was measured using the 4D Model developed by Buhmann and Ingenhoff (2015a).

The results show that a public diplomacy strategy designed for foreign publics can influence the country identity of the domestic public. This is in line with the case study of Huijgh and Byrne (2012), who found that "public diplomacy has provided a vehicle for the shaping and reshaping of national identity" and therefore there should be a reconceptualization in order to include a domestic dimension in public diplomacy. Thus, in an era where everyone can access almost every message, public diplomacy can affect more people than ever before. However, the differentiation of publics makes it difficult to create a strategy that is suitable for all of them. The effect of public diplomacy on country identity is moderated by the personal beliefs of the domestic public on the communicated issue, as well as the way in which it is communicated. Therefore, in modern times communicating something to a target public can only be done partially, as it must always be considered that the message might go around the globe and affect not only images of the country but also country identities.

\section{Limitations and future research}

Although the study contributes to the research gap in terms of its application of the quite recently developed 4D Model, its research design and its interest in the outcome rather than the output of public diplomacy, there are still limitations. The results are not generalizable due to the homogenous sample drawn from IP-Suisse. Another limitation of the study is its focus on the two biggest language regions of Switzerland, thereby showing only part of the national picture, as there are four language regions in total. Additionally, personal beliefs on the mass immigration initiative were measured by a single item asking the subjects how they voted (or if they did not, how they would have voted) on the initiative. However, a political belief on a controversial issue like the mass im- 
migration initiative is a complex construct and should therefore be measured with multiple different items in order to really capture the varied and complex personal beliefs of the subjects on this issue. As stated in the results, one limitation is that the undecided group is too small to calculate. This unprejudiced group might react completely differently to the different stimuli.

The study does reveal several directions for future research. Starting with Switzerland, there are four language regions and they might all have different country identities. It would be interesting to analyze all four of them as they could have different reactions to different public diplomacy strategies. However, the very small group of the Rhaeto-Romanic-speaking part of Switzerland might prove difficult to analyze. To gain a bigger sample, larger bilingual countries such as Belgium or Canada might be an option. In addition, the country identities of Switzerland could further be differentiated and analyzed, for example by including minority groups like naturalized foreigners, as foreign-born citizens represent about $25 \%$ of the population of Switzerland (BFS, 2015a). The comparisons could be done between country images, for example by comparing the effect of the minaret initiative in Switzerland on its country image in Muslim countries and European countries. But also to simply compare the country identities of different publics might provide interesting information about the composition of their country identities. This study showed how these compositions can differ between two ethnic groups even in a small country like Switzerland. In order to make further analyses comparable it would be reasonable to use the 4D Model for future examinations. Furthermore, it would be interesting to examine an issue which is less high profile in order to have a bigger group of undecided subjects. As the results showed, there were different effects on the supporters and opponents of the initiative. It would therefore be interesting to analyze how public diplomacy strategies affect previously undecided publics. Additionally, the reasons why an indicator or dimension is affected would shed some light onto the effect of public diplomacy on country identity. However, in order to achieve this, the research design would probably need to combine quantitative (i. e., measures of the country identity) and qualitative (i.e., understanding what exactly changed the attitude for one particular item or path) aspects.

\section{References}

Ajzen, I., \& Fishbein, M. (Eds.). (1980). Understanding attitudes and predicting social behaviour. Englewood Cliffs, N: Prentice-Hal.

BFS (2015a). Migration und Integration. Bundesamt für Statistik, retrieved from: $\mathrm{http} / / /$ www.bfs.admin.ch/bfs/portal/de/index/ themen/01/07/blank/key/01/01.html last visited 17.12.2015.

BFS (2015b). Stimmbeteiligung. Bundesamt für Statistik, retrieved from: http://www. bfs.admin.ch/bfs/portal/de/index/themen/17/03/blank/key/stimmbeteiligung. $\mathrm{html}$ last visited 16.09.2015.

BK (2015). Vorlage Nr. 580 Übersicht - Volksinitiative 14.02.2012 «Gegen Masseneinwanderung». Schweizerische Bundeskanzlei.

Buhmann, A., \& Ingenhoff, D. (2013). Advancing the Country Image Construct from a Public Relations Perspective: The Constitution of the County Image and its Effect on Travel Behavior. Paper presented at the EUPRERA 2013 Congress, Barcelona Spain.

Buhmann, A., \& Ingenhoff, D. (2015a). The 4D Model of the country image: An integrative approach from the perspective of communication management. International Communication Gazette, 77(1), 102-124. doi:10.1177/1748048514556986

Buhmann, A., \& Ingenhoff, D. (2015b). Advancing the country image construct from a public relations perspective: From model to measurement. Journal of Communication Management, 19(1). doi:10.1108/ Jcom-11-2013-0083

Cohen, J. (2013). Statistical power analysis for the behavioral sciences. Academic press.

Diamantopoulos, A., \& Winklhofer, H.M. (2001). Index construction with formative indicators: An alternative to scale development. Journal of Marketing Research, 38(2), 269-277. doi:10.1509/jmkr.38.2.269.18845 
Druckman, J. N., \& Nelson, K. R. (2003). Framing and deliberation: How citizens' conversations limit elite influence. American Journal of Political Science, 47(4), 729-745.

Eisenegger, M., \& Imhof, K. (2008). The true, the good and the beautiful: Reputation management in the media society. In Public Relations Research (pp. 125-146): Springer.

Entman, R.M. (2008). Theorizing mediated public diplomacy: The US case. International Journal of Press-Politics, 13(2), 87-102. doi:10.1177/1940161208314657

Fitzpatrick, K. R. (2012). Defining strategic publics in a networked world: Public diplomacy's challenge at home and abroad. The Hague Journal of Diplomacy, 7(4), 421-440.

Fornell, C., \& Bookstein, F. L. (1982). Two structural equation models: LISREL and PLS applied to consumer exit-voice theory. Journal of Marketing Research, 440-452. doi: $10.2307 / 3151718$

Golan, G. J., \& Viatchaninova, E. (2013). Government Social Responsibility in Public Diplomacy: Russia's strategic use of advertorials. Public Relations Review, 39(4), 403-405. doi:10.1016/j.pubrev.2013.09.011

Goodman, M., \&Wang, J. (2006). Public diplomacy and global business. Journal of Business Strategy, 27(3), 41-49. doi:10.1108/02756660610663826

Hair Jr, J. F., Hult, G. T. M., Ringle, C., \& Sarstedt, M. (2013). A primer on partial least squares structural equation modeling (PLS-SEM). Sage.

Harris, B. (2013). Diplomacy 2.0: the future of social media in nation branding. Exchange: The Journal of Public Diplomacy, $4(1), 3$.

Hatch, M. J., \& Schultz, M. (2000). Scaling the Tower of Babel: Relational differences between identity, image, and culture in organizations. In M. Schultz, M. J. Hatch, \& M.H. Larsen (Eds.), The expressive organization: Linking identity, reputation, and the corporate brand (pp. 11-35). Oxford, UK: Oxford University Press.

Henseler, J., Hubona, G., \& Ray, P.A. (2016). Using PLS path modeling in new technology research: Updated guidelines. Industrial Management \& Data Systems, 116(1), 2-20. doi:10.1108/Imds-09-2015-0382

Henseler, J., \& Sarstedt, M. (2013). Goodnessof-fit indices for partial least squares path modeling. Computational Statistics, 28(2), 565-580. doi:10.1007/s00180-012-0317-1

Hu, L.t., \& Bentler, P. M. (1999). Cutoff criteria for fit indexes in covariance structure analysis: Conventional criteria versus new alternatives. Structural equation modeling: a multidisciplinary journal, 6(1), 1-55.

Huijgh, E., \& Byrne, C. (2012). Opening the windows on diplomacy: A comparison of the domestic dimension of public diplomacy in Canada and Australia. The Hague Journal of Diplomacy, 7(4), 395-420.

Ingenhoff, D., \& Sommer, K. (2007). Does ethical behaviour matter? How corporate social responsibility contributes to organizational trustworthiness. Paper presented at the $57^{\text {th }}$ Annual Conference of the International Communication Association (ICA).

Ingenhoff, D., \& Sommer, K. (2010). Spezifikation von formativen und reflektiven Konstrukten und Pfadmodellierung mittels Partial Least Squares zur Messung von Reputation. Forschungsmethoden für die Markt-und Organisationskommunikation, 246-288.

Jarvis, C. B., MacKenzie, S. B., \& Podsakoff, P. M. (2003). A critical review of construct indicators and measurement model misspecification in marketing and consumer research. Journal of Consumer Research, 30(2), 199-218.

Khatib, L., Dutton, W., \& Thelwall, M. (2012). Public Diplomacy 2.0: A Case Study of the US Digital Outreach Team. Middle East Journal, 66(3), 453-472. doi:10.3751/66.3.14

Latzer, M., Aubert, V., Just, N., Korinth, L., \& Saurwein, F. (2012). Länderprofile der Mediennutzung. Forschungsbericht-Abteilung Medienwandel \& Innovation, 1-178. IPMZ, Universität Zürich, Zürich.

Levin, I. P., Schneider, S. L., \& Gaeth, G. J. (1998). All frames are not created equal: A typology and critical analysis of framing effects. Organizational behavior and human decision processes, 76(2), 149-188. doi:10.1006/ obhd.1998.2804

Lutz, G. (2015). Swiss Electoral Studies (Selects) 2015. Lausanne: FORS/Selects.

Melissen, J. (2005). The new public diplomacy: Soft power in international relations. Houndmills: Palgrave Macmillan. 
Mogensen, K. (2015). International trust and public diplomacy. International Communication Gazette, 1748048514568764.

Monecke, A., \& Leisch, F. (2012). semPLS: Structural Equation Modeling Using Partial Least Squares. Journal of Statistical Software, 48(3), 1-32. doi:10.18637/jss.v048.i03

Rusciano, F. L., Fiske-Rusciano, R., \&Wang, M. (1997). The impact of "world opinion" on national identity. The Harvard International Journal of Press/Politics, 2(3), 71-92. doi:10.1177/1081180x97002003006

Schmid, C. (1995). Comparative Intergroup Relations and Social Incorporation in Two Multilingual Societies: Canada and Switzerland. Occasional Paper No. 95-03.1.

Slothuus, R. (2008). More than weighting cognitive importance: A dual-process model of issue framing effects. Political Psychology, 29(1), 1-28.

Smith, A. D. (1986). The ethnic origins of nations. Oxford: Basil Blackwell.

Smith, A. D. (1991). National identity. London: Penguin Books.

Smith, A. D. (1996). Culture, community and territory: The politics of ethnicity and nationalism. International Affairs, 72(3), 445-458. doi:10.2307/2625550

Smyth, R. (2001). Mapping US public diplomacy in the 21st century. Australian Journal of International Affairs, 55(3), 421-444. doi:10.1080/10357710120095252

Strauss, N., Kruikemeier, S., van der Meulen, H., \& van Noort, G. (2015). Digital diplomacy in GCC countries: Strategic communication of Western embassies on Twitter. Government Information Quarterly. doi:10.1016/j.giq.2015.08.001

Tenenhaus, M., Amato, S., \& Esposito Vinzi, V. (2004). A global goodness-of-fit index for PLS structural equation modelling. Paper presented at the Proceedings of the XLII SIS scientific meeting.

Tenenhaus, M., Vinzi, V.E., Chatelin, Y.-M., \& Lauro, C. (2005). PLS path modeling. Computational Statistics \& Data Analysis, 48(1), 159-205.

Zhong, X., \& Lu, J.Y. (2013). Public diplomacy meets social media: A study of the US Embassy's blogs and micro-blogs. Public Relations Review, 39(5), 542-548. doi:10.1016/j. pubrev.2013.07.002 